\title{
A hydrological early warning system for Denmark based on the national model
}

\author{
Hans Jørgen Henriksen, Simon Stisen, Xin He and Marianne B. Wiese
}

The rapidly increasing impacts of climate change are likely to require changes in relevant institutions (IPCC 2012). An example is the growing need for immediate information on the entire water cycle (Fig. 1), with quantitative assessments of critical hydrological variables and flow interactions between different domains, e.g. atmosphere, plant-soil, surface water, groundwater and the sea, as they take place.

Potential measures include early warning systems, risk communication between decision makers and local citizens, sustainable land management, including land use planning as well as ecosystem management and restoration (IPCC 2012). Early warning systems (Kundzewicz 2013) that provide information and monitoring of past and present hydrological conditions as well as forecasting of hydrological conditions (e.g. water content, flow and water levels) are first steps in developing flooding indicators for operational use. It is possible that a nationwide system can be linked to local early warning systems and can make use of national overviews based on national hydrological models. Flooding and drought events are complex phenomena with several key mechanisms including intense and long lasting precipitation or lack of precipitation in the case of drought and interaction with water uses. Water consumers use groundwater for drinking water, food production, households and livestock, energy production and recreational

Fig. 1. Water balance in $\mathrm{mm} /$ year for a typical Danish area. With climate change the freshwater cycle is no longer in a steady state. Early warning and monitoring keeps us continuously updated and gives us an overview. This is important for our ability to combat the impact of climate change and manage the water resources proactively. activities. At the same time, water authorities have to manage surface and groundwater to sustain ecological systems, and support vital ecological conditions for plants and animals in rivers and wetlands. It is obvious that it is vital for society to have water in the right amount in the right place at the right time. Therefore, we must understand the water cycle, i.e. how overland drainage and surface runoff are generated, how water flows in the upper soil layers and in the deeper subsurface, how it is discharged in water courses and lakes and how freshwater interacts with the sea.

One or two decades ago, water management was developed and operated under the assumption of static conditions, a paradigm which now is dead according to Milly et al. (2008). It is stated by Milly et al. (2008, p. 573) that "Stationarity - the idea that natural systems fluctuate within an unchanging envelope of variability - is a foundational concept that permeates 
training and practice in water-resource engineering .... Stationarity is dead because substantial anthropogenic change of the Earth's climate is altering the means and extremes of precipitation, evapotranspiration, and rates of discharge of rivers". In the new paradigm, in the non-stationary world, real-time modelling and a continuity of monitoring systems are critical for dealing with the increasing impact of extremes. Globally natural disaster costs have more than quadrupled since 1985 (Georgieva 2014). Early warning and monitoring systems that can transfer operational hydrological knowledge to community-based climate change adaptation planning and emergency management, are assumed to be fundamental for building societal resilience, both in the phases of pre-disaster, disaster response and post-disaster, and in general for extending monitoring techniques with network-based public participation.

The Geological Survey of Denmark and Greenland (GEUS) financed a two year project (2012-2014), in order to determine the requirements for a hydrological system capable of providing real-time and forecast simulations based on a national hydrological model (the DK-model; www. vandmodel.dk; Henriksen et al. 2003; Stisen et al. 2012; Højberg et al. 2013), and how the system can be linked with local early warning systems. This paper describes four scenarios discussed at a participatory workshop in October 2014 and the workshop's outcome. The workshop provided GEUS with valuable insight and feedback relevant for the future development of a nation-wide, real-time modelling and water cycle monitoring system for Denmark, including the possible input to an early warning system and real-time forecasting to operate at local level.

\section{Structuring the needs - four scenarios for an early warning system design}

The four scenarios, used in the workshop, for the design of a hydrological, real-time forecasting system linked to local level, community-based, emergency management are shown in Fig. 2.

Scenario 1: An updated national model can provide an estimate of the actual status of water resources in Denmark based on the calibrated national model (the DK-model) with updated climatic data, and available on-line with absolute values, indices or anomalies (below, same as, or above normal).

Scenario 2: A national model that can forecast the state of the water resources on a short timescale or as a seasonal prognosis, based on forward modelling simulations using weather forecast data. This could be used as an early warning system and as a starting point for local, community-based emergency management.

Scenario 3: Decision Support is a scenario where local communities use a decision support tool for integrated assessment and management (Kelly et al. 2013), for incorporating local knowledge and experience, and where simulation results from the national model in forecasting mode are included. This scenario builds on a combination of monitored data and model output. The output from this model might be with physical variables, thematic maps, indices or anomalies.

Scenario 4: A complex local model where a local detailed model (such as MIKE 11 or MIKE Urban) uses simulated results from the national model in forecasting mode as input or boundary conditions. This can be combined with monitoring data in a data assimilation framework. The national model data in this scenario are physical variables delivered as point- or gridded data.

A representative catchment area (Skjern Å; Fig. 3) was selected for the workshop to test and demonstrate a prototype of a web-based, hydrological warning system for professional users. The system provides hydrological simulations from groundwater levels, stream flow and water content in the root zone. Webpages can be tailor-made to meet the requirements of end-users and continuously adapt to changing user demands. Numerical results from simulations on a national

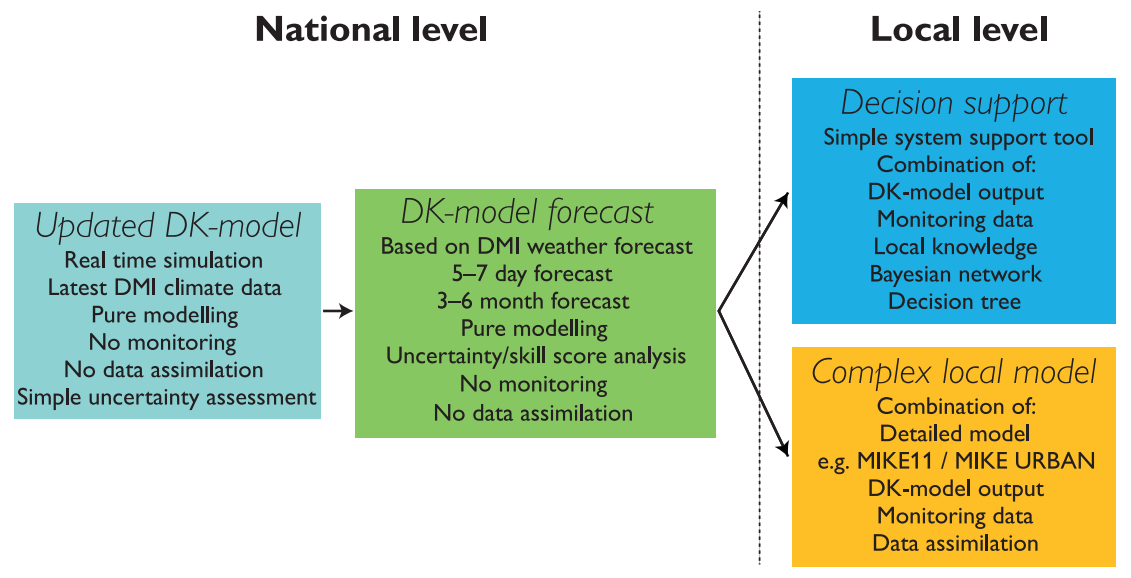

Fig. 2. The four real-time forecasting scenarios discussed in the text. Scenario 1: Updated DKmodel, Scenario 2: DK-model forecast, Scenario 3: Local decision support and Scenario 4: Complex local model. 
scale could also be provided. Hourly values of climatic and discharge data at Ahlergaarde Station 250082 were used for the prototype demonstration.

\section{Setting up the workshop}

A participatory workshop (Hare \& Krykow 2005) was held in Copenhagen for the purpose of eliciting stakeholder ideas and opinions and get feedback from prospective users. Participants were planners and emergency managers from local authorities, water supply companies, ministries and consulting agencies. The workshop had invited speakers from the Holstebro, Aarhus and Fredensborg municipalities and local authorities that had already implemented local, real-time forecasting and early warning systems. The Danish Hydraulic Institute (DHI) and the Danish Meteorological Institute (DMI), GEUS' two partners in the project, also presented their experiences. Both of these institutions have more than 20 years of experience developing and implementing modelbased early warning systems in Denmark and abroad.

Prior to the workshop, an invitation was sent to those employed with climate change adaptation and emergency management at local and national levels. A questionnaire was attached to the invitation which explained why GEUS had initiated the project, introduced the four scenarios and briefly described the hydrological components that the national model can simulate. The prototype of the web interface was described. The goal of the workshop was an in-depth discussion of user requirements as a supplement to the web questionnaire which had 27 respondents. A total of 34 participants signed up for the workshop; eight came from GEUS, one from DMI, one from DHI, nine from local authorities, four from national ministries, ten from consulting companies and one from a large water-supply company.

The workshop was a one day event. The first block contained three presentations by GEUS participants: introduction to the real-time project, technical challenges in real-time modelling and web presentation of real-time data for the river Skjern $\AA$ catchment area. This was followed by two invited presentations by DMI (better prediction of heavy rain) and the DHI (early warning systems in relation to hydrology and the freshwater cycle). Three invited speakers from local authorities talked about flooding from the river Stora in Holstebro, the Usserød Å project in Fredensborg and an early warning model with emphasis on flooding and groundwater monitoring in the urban area of Aarhus. Finally, there was a group session with three groups each addressing the same four questions. (1) What are the requirements for realtime forecasting? Do you miss an overview of the hydrological state of an area in your daily work or in situations with

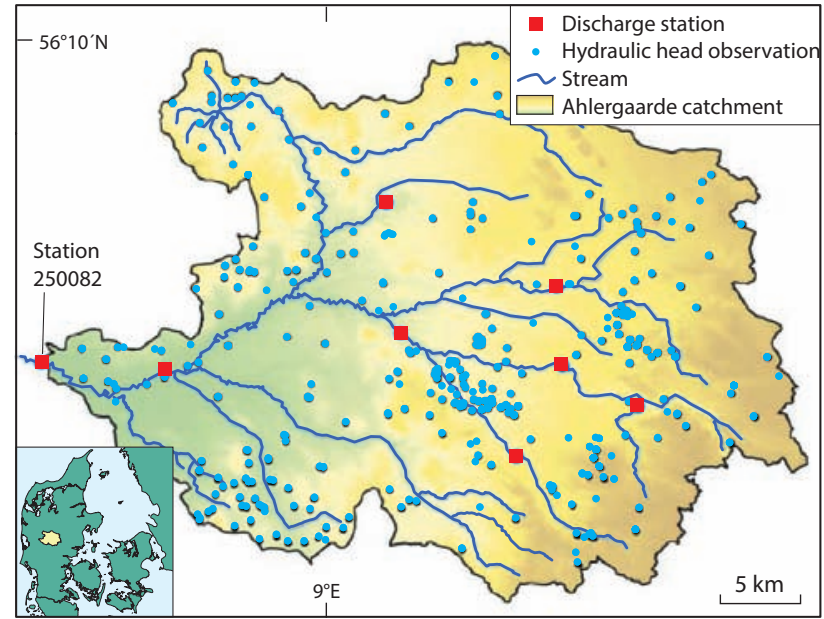

Fig. 3. Pilot case study for river Skjern Å, Ahlergaarde catchment area. Green: low elevation areas. Dark yellow: high elevation areas.

flooding or drought? (2) What information would be beneficial during such a situation, absolute or relative values; and which components of the hydrological cycle are the most important? (3) What is the time perspective in such an extreme event: days, hours or other? What would be the most appropriate frequency for updating the forecasts? (4) Would a national overview make any difference in forecasting hydrological events, and how can or should the prototype be developed further? How can the present DK-model be part of such a system?

\section{Outcome of the workshop}

The results of the discussions were presented by groups. Group 1 recommended linking national and local systems and presented a variety of requirements from different local authorities posing potential challenges to the entire concept. They noted that problems with flooding, drought and emergency management are highly site specific. Data assimilation is an important component in the early warning systems and there are many different sources of observational data, e.g. from local authorities and the Danish Road Directorate. A merged dataset is preferred.

Group 2 noted that real-time data for shallow groundwater levels are lacking but it may be possible to use observations from geotechnical boreholes. An investigation of geotechnical boreholes is necessary in order to establish a new operational groundwater level monitoring network. More emphasis should be given to a real-time early warning system instead of the present forecasting system with a short time horizon of only days. The quality of early warnings should be quantified in order to demonstrate how reliable the model can describe 
extremes. It is important to simulate water levels including storm surges. Data and forecasts should be available online.

Group 3 noted that in many cases local authorities have their own local data which could provide input to the national model. Local authorities may not have a groundwater model so co-operation between GEUS and local authorities are encouraged. Local authorities experience an increased demand for warning and action capabilities. At the same time, local authorities are reluctant to issue warnings because they do not wish to be overcautious or risk subsequent claims. Absolute values of physical variables are requested and data of levels of surface water and shallow groundwater are the most urgent. It was also suggested that continuous monitoring of water levels and early warning of changes in these levels are the most interesting for short-term forecasts, especially when local authorities do not have early warning systems, which is consistent with what was proposed by Group 2. From a temporal perspective, precipitation events are highly diverse and it may not always be the short-term cloudbursts that are the most influential. Long periods of rainfall (e.g. from a few days in succession to prolonged periods of rain) can significantly increase groundwater levels in western and central Jylland and snowmelting events can also cause extreme flooding. For the moment the national model has a limited applicability with its focus on water flow simulations. It is necessary to simulate water levels with local models.

\section{Discussion and conclusion}

A participatory workshop discussion real-time forecasting was held to get feedback and get into dialogue with water planners and emergency managers from local authorities, water companies and national authorities. At the workshop, a prototype website illustrating four scenarios of national and local early warning systems was presented for the Skjern $\AA$, Ahlergaarde catchment area with selected events. The workshop recommended that GEUS should focus on realtime modelling with the DK-model (Scenario 1). The first step is to update the national coverage of climatic data input from DMI; real-time discharge flow and groundwater level monitoring are required; and the necessity of data assimilation and other types of uncertainty analyses have to be further evaluated. If a forecast model is included (Scenario 2), complex data assimilation is required, however, this can compromise the water and mass balance of the model. The water balance and simulation of the whole water cycle should be addressed by the early warning systems (most participants found that soil moisture, discharge in rivers and groundwater levels should be represented in such a system). Eventually, an improved system for collecting observations of precipitation (or use of high-resolution radar measurements adjusted with rain-gauge data from a coarse network) is needed because the current network of rain-gauge stations has a poor national coverage. The early warning system should be able to deliver results for discharge stations and boundary conditions for subsequent use in local models (Scenarios 3 and 4).

\section{Acknowledgements}

The study was conducted as part of the GEUS-funded project: 'Realtidsvarsling'. The paper is a NORDRESS (nordress.hi.is) contribution. We are grateful for the input and feedback of the participants at the workshop.

\section{References}

Georgieva, K. 2014: Post-Haiyan - a way forward. Speech/14/441 by EU Commissioner for international cooperation, humanitarian aid and crisis response. ASEM Conference on Disaster Risk Reduction and Management. Manila, 5 June 2014.

Hare, M. \& Krykow, J. 2005: Participatory processes for the design of water storage areas - theme group III inception report of the TRUST project. Seecon report 1/2005, 68 pp. Osnabrück: Hoogheemraadschap van Schielanden en der Krimpenerwaard.

Henriksen, H.J., Troldborg, L., Nyegaard, P., Sonnenborg, T.O., Refsgaard, J.C. \& Madsen, B. 2003: Methodology for construction, calibration and validation of a national hydrological model for Denmark. Journal of Hydrology 280, 52-71.

Højberg, A.L., Troldborg, L., Stisen, S., Christensen, B.S.B. \& Henriksen, H.J. 2012: Stakeholder driven update and improvement of a national water resources model. Environmental Modelling and Software 40, 202-213.

IPCC 2012: Managing the risks of extreme events and disasters to advance climate change adaptation, a special Report of working groups I and II of the Intergovernmental Panel on Climate Change, 582 pp. Cambridge: Cambridge University Press.

Kelly, R.A. et al. 2013: Selecting among five common modelling approaches for integrated environmental assessment and management. Environmental Modelling \& Software 47, 159-181.

Kundzewicz, Z.W. 2013: Floods: lessons about early warning systems. In: Gee, D. et al. (eds): Late lessons from early warnings: science, precaution, innovation, 347-368. EEA Report no. 1/2013. Copenhagen: European Environment Agency.

Milly, P.C.D., Betancourt, J., Falkenmark, M., Hirsch, R.M., Kundzewicz, Z.W., Lettenmaier, D.P. \& Stouffer, R.J. 2008: Stationarity is dead: Whither water management? Science 319, 573-574.

Stisen, S., Højbjerg, A.L., Troldborg, L., Refsgaard, J.C., Christensen, B.S.B., Olsen, M. \& Henriksen, H.J. 2012: On the importance of appropriate precipitation gauge catch correction for hydrological modelling at mid to high latitudes. Hydrology and Earth System Sciences 16, $4157-4176$

\footnotetext{
Authors' address

Geological Survey of Denmark and Greenland, ØsterVoldgade 10,DK-1350 Copenhagen K, Denmark. E-mail: hjh@geus.dk
} 